\title{
Características produtivas, estruturais e bromatológicas dos capins Tifton 85 e Piatã e do feijão-guandu cv. Super N, em cultivo singular ou em associação
}

\author{
Productive, structural and bromatological characteristics of Tifton 85 and Piatã grasses and of \\ pigeonpea cv. Super N, in single or mixed
}

\author{
Marcela Abbado Neres ${ }^{\text {* }}$ Deise Dalazen Castagnara ${ }^{\text {II }}$ Francieli Batista Silva ${ }^{\text {III }}$ \\ Paulo Sérgio Rabello de Oliveira' ${ }^{\mathrm{I}}$ Eduardo Eustáquio Mesquita ${ }^{\mathrm{I}}$ Taimara Carla Bernardi $^{\mathrm{IV}}$ \\ Alcir João Guarianti ${ }^{\mathrm{IV}}$ Alex Sérgio Lazaretti Vogt $^{\mathrm{IV}}$
}

\section{RESUMO}

Objetivou-se avaliar características produtivas, estruturais e nutricionais dos capins Tifton 85 e Piatã e da leguminosa feijão-guandu em monocultivo ou em cultivo consorciado, com e sem aplicação de nitrogênio. Adotou-se o delineamento de blocos casualizados com parcelas subdivididas no tempo, com sete tratamentos nas parcelas principais e 3 tempos de avaliação nas sub-parcelas, com 4 repetições. Os tratamentos consistiram: Cajanus cajan cv. 'Super $N$ ' (feijãoguandu); Brachiaria brizantha $\mathrm{cv}$. 'Piatã' solteira sem aplicação de nitrogênio (N); B. brizantha cv. 'Piatã' em associação com feijão guandu; B. brizantha $\mathrm{cv}$. 'Piatã' solteira com aplicação de N (150 kg ha-1); Cynodon sp. Tifton 85 em cultivo solteiro sem aplicação de $\mathrm{N}$; Tifton 85 em associação com feijãoguandu e Tifton 85 com aplicação de $N\left(150 \mathrm{~kg} \mathrm{ha}^{-1}\right)$ e três períodos de avaliações. A associação dos capins Piatã e Tifton $85 \mathrm{com}$ feijão-guandu proporcionou produção forrageira equivalente à adubação nitrogenada e incrementos com elevação nos teores de proteína bruta e redução nos teores de fibra em detergente neutro. O capim Tifton 85 se mostrou menos tolerante ao sombreamento imposto pelo feijão-guandu.

Palavras-chave: Brachiaria, Cynodon, nitrogênio, proteína bruta.

\section{ABSTRACT}

This trial aimed at evaluating characteristics as: production, structural and nutritional requirements of Tifton 85 and Piatã grasses and pigeonpea in single or intercropped tillage, with and without nitrogen application. The experimental plot in randomized blocks with plots subdivided through time, with 7 treatments in the main plots and three periods of evaluation on subplots with four replications. The studied

\begin{abstract}
treatments were: Cajanus cajan cv. Super $N$ (pigeonpea), Brachiaria brizantha $c v$. single Piatã without application of nitrogen $(N)$; B. brizantha $c v$. Piatã in association with pigeonpea; B. brizantha $\mathrm{cv}$. single Piatã with application of $N$ (150kg ha-1); Cynodon sp. Tifton 85 in a single crop without application of $\mathrm{N}$; Tifton 85 in association with pigeonpea and Tifton 85 plus an application of $N\left(150 \mathrm{~kg} \mathrm{ha}^{-1}\right)$ and three cycles of evaluations. The association of Tifton 85 and Piatã grasses with pigeonpea provided forage production like nitrogen fertilizer and increase crude protein content and a reduction on neutral detergent fiber contents. Tifton grass was less tolerant to shading from pigeonpea.
\end{abstract}

Key words: Brachiaria, crude protein, Cynodon, nitrogen.

\section{INTRODUÇÃO}

A produção animal a pasto nos trópicos caracteriza-se pelo extrativismo, porém esse modelo de exploração compromete a sustentabilidade, acarretando a perda da capacidade produtiva do sistema (BARCELLOS et al., 2008). A manutenção do potencial produtivo de áreas de pastagens pode ser obtida através da utilização de adubações de manutenção, especialmente a adubação nitrogenada. Entretanto, essa é uma prática utilizada com pouca frequência em pastagens tropicais, devido principalmente aos altos custos dos fertilizantes nitrogenados e ao caráter extensivo da atividade pecuária, comprometendo a

ICentro de Ciências Agrárias (CCA), Universidade Estadual do Oeste do Paraná (UNIOESTE), Rua Pernambuco, 1777, CP 91, 85960-000, Marechal Cândido Rondon, PR, Brasil. E-mail: mabbadoneres@yahoo.com.br. *Autor para correspondência.

IIPrograma de Pós-graduação em Agronomia, CCA, UNIOESTE, Marechal Cândido Rondon, PR, Brasil.

IIIPrograma de Pós-graduação em Zootecnia, CCA, UNIOESTE, Marechal Cândido Rondon, PR, Brasil.

${ }^{\mathrm{IV}}$ Graduação em Zootecnia, CCA, UNIOESTE, Marechal Cândido Rondon, PR, Brasil. 
produção das gramíneas forrageiras e, consequentemente, a produção animal (MONTEIRO et al., 2002).

Diante da importância que as pastagens desempenham para a maioria dos modelos de produção praticados, é fundamental que seu uso esteja condicionado a práticas sustentáveis de manejo, que garantam a manutenção da produtividade ao longo dos anos sem comprometer os componentes principais do ecossistema. Dentre as alternativas de manejo disponíveis para pastagens de gramíneas tropicais, além da utilização de adubações de manutenção e do ajuste das taxas de lotação, a associação com leguminosas representa uma alternativa promissora, principalmente por representar uma tecnologia poupadora de insumos.

A introdução de leguminosas na pastagem promove incrementos na produção animal, pela qualidade e quantidade da forragem em oferta, tanto pela participação da leguminosa na dieta animal, quanto pelos efeitos indiretos relacionados com a fixação biológica de nitrogênio e seu repasse ao ecossistema da pastagem. ALMEIDA et al. (2003) e AROEIRA et al. (2005) observaram melhora no valor nutritivo e aumento no consumo de forragem ao estudarem a Brachiaria decumbens consorciada com Stylosanthes guianensis.

Entretanto, ainda são escassas as informações a respeito dos capins Tifton 85 e Piatã em cultivo consorciado com leguminosas. Assim, o presente estudo objetivou avaliar a produção de forragem, e as características estruturais e bromatológicas da forragem produzida pelos capins Tifton 85 e Piatã consorciados com feijão-guandu ou sob adubação nitrogenada.

\section{MATERIAL E MÉTODOS}

O experimento foi conduzido a campo, na Fazenda Experimental da Universidade Estadual do Oeste do Paraná, campus de Marechal Cândido Rondon - PR (24' 33'S, 54 $04^{\circ}$ ' W, e altitude de 420m). Segundo Köppen, o clima local é do tipo Cfa, subtropical com chuvas bem distribuídas durante o ano e verões quentes (IAPAR, 2006). Durante o período de implantação (janeiro de 2009) e coleta de dados (outubro de 2009 a janeiro de 2010), as temperaturas médias, máximas e mínimas variaram, respectivamente, entre 15 a $25 ; 22$ a 33 e 11 a $22^{\circ} \mathrm{C}$, enquanto as precipitações mantiveram-se próximas ou acima de 100mm mensais.

O Latossolo Vermelho eutroférrico (EMBRAPA, 2006) do local apresentou as características químicas (0-20cm): pH (água): 5,1; P (Mehlich): 8,3mg $\mathrm{dm}^{-3} ; \mathrm{K}$ (Mehlich): 0,2 $\mathrm{cmol}_{\mathrm{c}} \mathrm{dm}^{-3} ; \mathrm{Ca}^{2+}\left(\mathrm{KCl} 1 \mathrm{~mol} \mathrm{~L}^{-1}\right)$ : $4,6 \mathrm{cmol}_{\mathrm{c}} \mathrm{dm}^{-3} ; \mathrm{Mg}^{2+}\left(\mathrm{KCl} 1 \mathrm{~mol} \mathrm{~L}^{-1}\right): 2,2 \mathrm{cmol}_{\mathrm{c}} \mathrm{dm}^{-3} ; \mathrm{Al}^{3+}$ $\left(\mathrm{KCl} 1 \mathrm{~mol} \mathrm{~L}^{-1}\right): 4,1 \mathrm{cmol}_{\mathrm{c}} \mathrm{dm}^{-3} ; \mathrm{H}+\mathrm{Al}$ (acetato de $\mathrm{Ca}$ 0,5mol $\left.\mathrm{L}^{-1}\right): 6,1 \mathrm{cmol}_{\mathrm{c}} \mathrm{dm}^{-3}$; CTC: $13,1 \mathrm{cmol}_{\mathrm{c}} \mathrm{dm}^{-3}$; V: 53,1\%, MO: $28 \mathrm{~g} \mathrm{dm}^{-3} \mathrm{e}$ argila (EMBRAPA, 1997): $65 \%$.

O delineamento experimental adotado foi em blocos casualizados com parcelas subdivididas no tempo com sete tratamentos nas parcelas principais e três épocas de avaliação nas subparcelas, com quatro repetições. Os tratamentos alocados nas parcelas foram: $\boldsymbol{C}$. cajan cv. 'Super N' (feijão-guandu); $\boldsymbol{B}$. brizantha cv. 'Piatã' em monocultivo sem aplicação de nitrogênio (N); B. brizantha cv. 'Piatã' em associação com feijão-guandu; $\boldsymbol{B}$. brizantha cv. 'Piatã' solteira com aplicação de N; Cynodon spp. Tifton 85 em monocultivo sem aplicação de N; Tifton 85 em associação com feijão-guandu e Tifton 85 com aplicação de N. A adubação com N constituiu da aplicação $150 \mathrm{~kg}$ ha $^{-1}$ na forma de ureia, parcelada em $50 \mathrm{~kg} \mathrm{ha}^{-1}$ de $\mathrm{N}$ após cada corte, e três períodos de avaliação durante a primavera/verão.

O experimento foi implantado manualmente, em janeiro de 2009, respeitando-se uma densidade de sementes de $20 \mathrm{~kg} \mathrm{ha}^{-1}$ para o feijão-guandu (VC: 70\%) e $12 \mathrm{~kg} \mathrm{ha}^{-1}$ para o capim Piatã (VC: $30 \%$ ), enquanto para o capim Tifton 85 foram utilizadas mudas. As mudas foram obtidas por meio de estaquia e preparadas com estolões maduros com três gemas viáveis cultivadas por 30 dias em bandejas com substrato da marca PLANTMAX ${ }^{\circledR}$ sem a utilização de adubação. As parcelas possuíam área de $18 \mathrm{~m}^{2}(3,6 \times 5,0 \mathrm{~m})$, e adotouse o espaçamento entre linhas de $1,20 \mathrm{~m}$ para o feijãoguandu e de 0,30 e 0,20m para as gramíneas Piatã e Tifton 85, respectivamente. Nos consórcios, a cada três linhas de gramíneas, semeou-se uma linha de feijãoguandu, mantendo-se o espaçamento recomendado para o feijão-guandu de $1,20 \mathrm{~m}$.

Antes do plantio (60 dias), realizou-se calagem com calcário dolomítico, de acordo com análise de solo, para elevação da saturação por bases a 70\%. Como adubação de implantação, distribuiu-se manualmente nas linhas de semeadura e/ou plantio, $100 \mathrm{~kg} \mathrm{ha}^{-1}$ de $\mathrm{P}_{2} \mathrm{O}_{5}$ e $60 \mathrm{~kg} \mathrm{ha}^{-1}$ de $\mathrm{K}_{2} \mathrm{O}$ nas formas de superfosfato simples e cloreto de potássio, respectivamente.

Para o início das avaliações, foi realizado um corte de uniformização, em setembro de 2010, com roçadeira costal a $0,10 \mathrm{~m}$ de altura com posterior aplicação da primeira dose de $\mathrm{N}$ em cobertura. As avaliações foram realizadas durante os meses de outubro e dezembro de 2009 e janeiro de 2010, com intervalos aproximados de 55 dias, conforme a rebrota do feijão-guandu. A produção de matéria seca (MS) 
das gramíneas foi estimada por meio de amostragem com quadro metálico com área conhecida $\left(1 \mathrm{~m}^{2}\right)$, em altura de 0,10m para o Tifton 85 e 0,20m para o capim Piatã, lançado ao acaso na área útil de cada parcela. No feijão-guandu, realizou-se o pastejo simulado com a coleta manual das folhas e porções tenras dos caules de $1 \mathrm{~m}$ linear em cada parcela. As amostras foram pesadas, determinando-se a produção de matéria verde, e submetidas à secagem em estufa com ventilação forçada de ar sob temperatura de $55^{\circ} \mathrm{C}$ por 72 horas para a estimativa da produção de MS. Após cada amostragem, as gramíneas foram roçadas com roçadeira costal, respeitando-se as alturas de amostragem, enquanto no feijão-guandu foi realizado o pastejo simulado em todas as plantas.

Por meio da amostragem aleatória de 10 perfilhos de cada parcela, foram estudadas as características estruturais das gramíneas, avaliandose o número de folhas por perfilho (NFP), por meio de contagem manual das folhas sem sinais de senescência; o diâmetro de colmo (DC), mensurado na base de cada perfilho com auxílio de paquímetro digital; o comprimento do colmo (CC); e comprimento final de folhas (CFF), mensurados com auxílio de régua graduada em centímetros. A relação folha/colmo das gramíneas foi determinada por meio da razão entre os pesos secos de lâminas foliares e de colmos+bainhas, obtidos pela separação manual e secagem em estufa sob temperatura de $55^{\circ} \mathrm{C}$ por 72 horas. A altura do dossel forrageira $(\mathrm{ADF})$ foi mensurada com régua em cinco pontos distintos em cada parcela.

No estudo da composição químicobromatológica, as amostras secas foram trituradas e passadas em peneira de 30 mesh, para a determinação dos teores de proteína bruta (PB), segundo a AOAC (1990), fibra em detergente neutro (FDN), fibra em detergente ácido (FDA), celulose, hemicelulose e lignina, conforme SILVA \& QUEIROZ (2006).

Os dados obtidos foram submetidos à análise de variância e testados pelo teste F de Fischer. Quando constatado efeito significativo das fontes de variação, as médias foram comparadas por meio do teste de Tukey, em nível de 5\% de probabilidade (PIMENTEL-GOMES, 2009).

\section{RESULTADOS E DISCUSSÃO}

Houve efeito significativo da interação dos fatores para a altura do dossel forrageiro $(\mathrm{P}<0,05)$. No $1^{\circ}$ corte, a altura do dossel (Tabela 1$)$ do capim Piatã foi superior ao Tifton 85 ( $\mathrm{P}>0.05$ ). No $2^{\circ}$ corte, verificouse o mesmo comportamento para o capim Piatã em relação ao Tifton 85, porém, quando associado com feijão-guandu, apresentou menor altura em relação ao capim Piatã em monocultivo ou com adubação nitrogenada. As avaliações realizadas no $3^{\circ}$ corte revelaram novamente dois grupos distintos, com as maiores alturas para o capim Piatã e as menores para o capim Tifton 85, porém, a associação ao feijão-guandu proporcionou menor altura de dossel ao Tifton 85 (Tabela 1). Quando se comparou a altura do dossel entre os períodos avaliados, esta aumentou para todos os tratamentos. As reduções na altura do dossel forrageiro observadas para os capins Piatã e Tifton 85 podem estar relacionadas com o sombreamento imposto pelo feijão-guandu, pois essa leguminosa apresenta hábito de crescimento arbustivo, com atura média de 1,5m (DEMINICIS, 2009). Apesar de ainda serem escassos os estudos que tratam dos efeitos do sombreamento em gramíneas forrageiras, SANTOS et al. (2006) constataram redução no crescimento do Tifton 85 sombreado.

Houve significância da interação dos fatores para o número de folhas por perfilho, que foi maior no capim Tifton 85 no $1^{\circ}$ e $2^{2}$ - cortes estudados (Tabela 1 ). No $3^{\circ}$ corte, o capim Tifton 85 solteiro ou sob adubação nitrogenada apresentou número de folhas superior aos demais cultivos. O capim Piatã sem $\mathrm{N}$, ou associado ao feijão-guandu apresentou número de folhas semelhante ao capim Tifton 85 associado ao feijão-guandu, enquanto a aplicação de $\mathrm{N}$ ou o consórcio com feijãoguandu proporcionaram ao capim Piatã número de folhas semelhante (Tabela 1). Com o decorrer dos cortes, o número de folhas manteve-se constante no capim Piatã sob adubação nitrogenada e no Tifton 85 associado ao feijão guandu, enquanto, para os demais cultivos, foi observado aumento no número de folhas (Tabela 1). As diferenças observadas devem-se às características de cada espécie, e concordam com resultados de outras pesquisas. PEREIRA et al. (2011), ao estudarem o capim Tifton 85 sob doses de $\mathrm{N}$ e alturas de corte, encontraram até 9 folhas vivas por perfilho, e SILVEIRA et al. (2010) observaram 5,8 folhas por perfilho para o capim Piatã.

O comprimento final de folhas foi alterado pela interação dos fatores, sendo superior no capim Piatã em todos os cortes (Tabela 1). Entretanto, no $1^{\text {o }}$ corte, o capim Piatã consorciado com feijão-guandu apresentou comprimento de folhas inferior ao solteiro ou sob adubação nitrogenada, enquanto, para o Tifton 85, o menor comprimento final de folhas foi observado com a aplicação de N. Ao serem comparados os cortes, no capim Piatã consorciado e no Tifton 85 com N, houve, respectivamente, elevação e redução no comprimento de folhas, sem diferenças para os demais cultivos. As variações observadas para o comprimento 
Tabela 1 - Características estruturais da Brachiaria brizantha cv. 'Piatã', Cynodon spp. cv. 'Tifton 85’ e feijão-guandu em monocultivo, em consórcio ou com a utilização de adubação nitrogenada.

\begin{tabular}{|c|c|c|c|c|c|c|}
\hline \multirow{2}{*}{ Cultivos } & \multicolumn{3}{|c|}{ 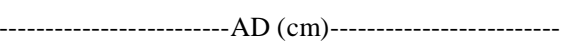 } & \multicolumn{3}{|c|}{-----------NFP (folhas perfilho ${ }^{-1}$ ) ------------ } \\
\hline & $1^{\circ}$ Corte & $2^{\underline{0}}$ Corte & $3^{0}$ Corte & $1^{\circ}$ Corte & $2^{\underline{0}}$ Corte & $3^{0}$ Corte \\
\hline Piatã & $67,50 \mathrm{aB}$ & $109,50 \mathrm{aA}$ & $110,00 \mathrm{aA}$ & $3,250 \mathrm{bB}$ & $4,083 \mathrm{bB}$ & $5,887 \mathrm{bA}$ \\
\hline Piatã $+N$ & $69,33 \mathrm{aB}$ & 109,17 aA & $112,92 \mathrm{aA}$ & 3,987 bA & $4,500 \mathrm{bA}$ & $4,420 \mathrm{cA}$ \\
\hline Piatã+Guandu & $65,00 \mathrm{aC}$ & 92,89 bB & 113,75 aA & $3,812 \mathrm{bB}$ & $4,937 \mathrm{bA}$ & 5,397 bcA \\
\hline Tifton & $42,33 \mathrm{bB}$ & $64,50 \mathrm{cA}$ & $72,50 \mathrm{bA}$ & $6,667 \mathrm{aB}$ & $6,917 \mathrm{aAB}$ & $7,863 a A$ \\
\hline Tifton $+\mathrm{N}$ & $40,75 \mathrm{bB}$ & $51,92 \mathrm{cB}$ & $67,33 \mathrm{bA}$ & $6,375 \mathrm{aC}$ & 7,417 aB & 8,553 aA \\
\hline Tifton+Guandu & 37,42 bB & $57,00 \mathrm{cA}$ & $60,55 \mathrm{cA}$ & 6,540 aA & 6,645 aA & 6,247 bA \\
\hline CV1\% & \multicolumn{3}{|c|}{7,86} & \multicolumn{3}{|c|}{10,02} \\
\hline \multirow[t]{2}{*}{$\mathrm{CV} 2 \%$} & \multicolumn{3}{|c|}{9,80} & \multicolumn{3}{|c|}{10,59} \\
\hline & \multicolumn{3}{|c|}{ 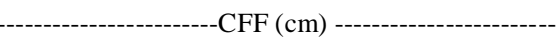 } & \multicolumn{3}{|c|}{ 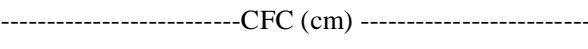 } \\
\hline Piatã & 39,143 bA & $39,010 \mathrm{aA}$ & 38,487 aA & $30,75 \mathrm{aB}$ & $58,66 \mathrm{abA}$ & 80,16 aA \\
\hline Piatã+N & 39,333 bA & 38,163 aA & 36,673 aA & $27,87 \mathrm{aB}$ & $63,08 \mathrm{aA}$ & 70,33 abA \\
\hline Piatã+Guandu & $44,53 \mathrm{aA}$ & $40,935 \mathrm{aAB}$ & $39,380 \mathrm{aB}$ & $35,67 \mathrm{aB}$ & 62,75 aA & 64,38 bcA \\
\hline Tifton & 20,153 cA & 22,767 bA & $20,493 \mathrm{bA}$ & $24,83 \mathrm{aB}$ & $55,08 \mathrm{abA}$ & $53,17 \mathrm{cdA}$ \\
\hline Tifton $+\mathrm{N}$ & $15,082 \mathrm{~dB}$ & $21,250 \mathrm{bB}$ & $16,557 \mathrm{bA}$ & $28,24 \mathrm{aB}$ & 50,12 bA & 48,33 cA \\
\hline Tifton+Guandu & $21,285 \mathrm{cA}$ & $21,937 \mathrm{bA}$ & 20,867 bA & $32,29 \mathrm{aB}$ & 47,58 bA & $53,57 \mathrm{cdA}$ \\
\hline CV1\% & \multicolumn{3}{|c|}{8,76} & \multicolumn{3}{|c|}{10,21} \\
\hline \multirow[t]{2}{*}{$\mathrm{CV} 2 \%$} & \multicolumn{3}{|c|}{6,97} & \multicolumn{3}{|c|}{11,91} \\
\hline & \multicolumn{3}{|c|}{ 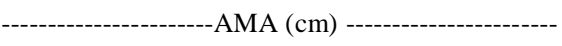 } & -------------. & ---F:C----. & ---------------- \\
\hline Piatã & $19,30 \mathrm{aC}$ & 73,90 aB & $87,08 \mathrm{aA}$ & $1,89 \mathrm{bA}$ & 0,84 bcB & $0,62 \mathrm{aC}$ \\
\hline Piatã+N & $20,49 \mathrm{aC}$ & $74,51 \mathrm{aB}$ & $85,50 \mathrm{aA}$ & $2,30 \mathrm{aA}$ & $0,97 \mathrm{abB}$ & $0,63 \mathrm{aC}$ \\
\hline Piatã+Guandu & $17,80 \mathrm{aC}$ & $69,45 \mathrm{aB}$ & $88,24 \mathrm{aA}$ & $1,61 \mathrm{cA}$ & $1,06 \mathrm{aB}$ & $0,57 \mathrm{aC}$ \\
\hline Tifton & 7,13 aC & $11,15 \mathrm{bB}$ & 23,66 bA & $1,18 \mathrm{de} A$ & $0,70 \mathrm{cB}$ & $0,55 \mathrm{aB}$ \\
\hline Tifton+N & $5,10 \mathrm{aC}$ & 10,15 bB & 20,50 bcA & $1,33 \mathrm{dA}$ & $0,64 \mathrm{cdB}$ & $0,51 \mathrm{aB}$ \\
\hline Tifton+Guandu & $4,67 \mathrm{aC}$ & $13,50 \mathrm{bB}$ & 22,50 cA & $1,04 \mathrm{eA}$ & $0,44 \mathrm{dC}$ & 0,69aB \\
\hline CV1\% & \multicolumn{3}{|c|}{10,87} & \multicolumn{3}{|c|}{9,60} \\
\hline CV2\% & \multicolumn{3}{|c|}{9,04} & \multicolumn{3}{|c|}{10,31} \\
\hline
\end{tabular}

*Valores seguidos de mesma letra, maiúscula na linha e minúscula na coluna, não diferem entre si pelo teste Tukey a 5\%. NFP: número de folhas verdes por perfilho; CFF: comprimento final de folhas; CFC: comprimento final de colmo; AD: altura do dossel forrageiro; AMA: altura do mersitema apical; F:C: relação folha/colmo; CV1 (\%): coeficiente de variação da parcela; CV2 (\%): coeficiente de variação da subparcela.

de folhas se devem às características de cada espécie, e são coerentes com resultados de outros trabalhos (SILVEIRA et al., 2010; PEREIRA et al., 2011; PREMAZZI et al., 2011).

As diferenças entre as espécies quanto ao comprimento final do colmo revelou significância para a interação dos fatores, e tornaram-se marcantes com o passar dos cortes, revelando o maior potencial do capim Piatã no alongamento do colmo, conforme já descrito por GOMIDE et al. (2007) para gramíneas forrageiras tropicais. O rápido alongamento do colmo (BARBOSA et al., 2007) é capaz de condicionar o comportamento ingestivo e o desempenho dos animais (GONTIJO NETO et al., 2006), e sua ocorrência sob condições climáticas favoráveis (época chuvosa) já foi relatada por outros autores (CANDIDO et al., 2005; CARNEVALLI et al., 2006; BARBOSA et al., 2007).
Com o passar dos cortes, houve elevação do meristema apical em todas as gramíneas, sendo que no $1^{\circ}$ corte não houve diferença significativa entre tratamentos. A partir do $2^{\circ}$ corte, a altura do meristema apical foi superior no capim Piatã, com valor médio de 72,62cm mantendo mesmo comportamento no $3^{\circ}$ corte. A elevação do meristema apical é importante no manejo das pastagens, pois a eliminação deste com o corte ou pastejo leva a um maior tempo de rebrota das plantas, que se realizará a partir das gemas laterais e implicará um maior consumo de reservas.

A relação folha/colmo no $1^{\circ}$ e $2^{\underline{0}}$ corte foi menor no Tifton 85, enquanto no $3^{\circ}$ corte não houve diferenças entre os tratamentos, porém foram observados decréscimos com o passar dos cortes, devido às condições climáticas favoráveis ao desenvolvimento das plantas, que favorecem o 
alongamento dos colmos (CARNEVALLI et al., 2006). A baixa relação folha/colmo para o capim Tifton 85 e o maior comprimento de folhas do capim Piatã no primeiro corte, quando associados ao feijão-guandu se devem ao sombreamento imposto pela leguminosa. Segundo GOBBI et al. (2009), o alongamento das lâminas foliares e alterações na relação folha/colmo estão entre as principais respostas morfofisiológicas manifestadas pelas gramíneas em condições de sombreamento, enquanto SOARES et al. (2009) observaram que, em condições de luminosidade reduzida, as folhas modificam sua estrutura e se tornam maiores, mais tenras e estioladas.

Os teores de PB, FDN, FDA, hemicelulose, celulose e lignina foram alterados pela interação dos fatores (Tabela 2). Verificou-se que os teores de PB no $1^{\circ}$ e no $3^{\circ}$ corte foram superiores para a forragem obtida com a leguminosa ou com sua associação com as gramíneas em relação ao monocultivo ou à utilização de N. Ao longo dos cortes, foi observado comportamento distinto para os valores de PB, devido às variações observadas nas proporções de gramíneas e leguminosas que compuseram a forragem avaliada (Tabela 3). Os resultados evidenciam o papel fundamental da presença da leguminosa na elevação dos teores de PB da forragem ofertada aos animais. Os valores obtidos mantiveram-se superiores ou próximos aos obtidos por COSTA et al. (2005) ao trabalharem com B. brizantha e SANTOS et al. (2008) com Tifton 85. Considerando que PB inferior a 7\% limita o consumo

Tabela 2 - Características bromatológicas da Brachiaria brizantha cv. 'Piatã', Cynodon spp. cv. 'Tifton 85' e feijão-guandu em monocultivo, em consórcio ou com a utilização de adubação nitrogenada.

\begin{tabular}{|c|c|c|c|c|c|c|}
\hline \multirow{2}{*}{ Cultivos } & \multicolumn{3}{|c|}{ 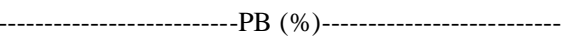 } & \multicolumn{3}{|c|}{ 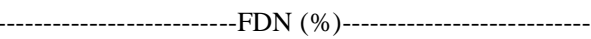 } \\
\hline & $1^{0}$ Corte & $2^{\underline{0}}$ Corte & $3^{\circ}$ Corte & $1^{\circ}$ Corte & $2^{\circ}$ Corte & $3^{0}$ Corte \\
\hline Piatã & $10,00 \mathrm{dA}$ & $9,07 \mathrm{cA}$ & $8,15 \mathrm{dA}$ & $75,85 \mathrm{bB}$ & 80,67 abA & $81,97 \mathrm{bA}$ \\
\hline Piatã+N & $11,47 \mathrm{dA}$ & $9,21 \mathrm{cA}$ & $9,24 \mathrm{dA}$ & $70,12 \mathrm{cB}$ & 80,06 bA & $80,60 \mathrm{bA}$ \\
\hline Piatã+Guandu & $16,28 \mathrm{bA}$ & $11,61 \mathrm{cB}$ & $17,8 \mathrm{cA}$ & $66,52 \mathrm{cB}$ & $71,26 \mathrm{cA}$ & $67,77 \mathrm{cdAB}$ \\
\hline Tifton & $12,29 \mathrm{cdA}$ & 9,17 cB & $11,51 \mathrm{dAB}$ & 83,33 aA & 85,79 aA & 84,72 abA \\
\hline Tifton+N & $11,57 \mathrm{cdA}$ & $8,30 \mathrm{cB}$ & $10,45 \mathrm{dAB}$ & $81,66 \mathrm{aB}$ & $85,80 \mathrm{aAB}$ & 88,28 aA \\
\hline Tifton+Guandu & 15,54 bcB & $16,41 \mathrm{bB}$ & 21,89 bA & $69,99 \mathrm{cB}$ & 75,34 bcA & $68,94 \mathrm{cB}$ \\
\hline Guandu & $25,40 \mathrm{aB}$ & $23,53 \mathrm{aB}$ & $33,50 \mathrm{aA}$ & $46,59 \mathrm{~dB}$ & $61,85 \mathrm{dA}$ & $62,58 \mathrm{dA}$ \\
\hline CV1\% & \multicolumn{3}{|c|}{7,38} & \multicolumn{3}{|c|}{3,26} \\
\hline \multirow[t]{2}{*}{ CV2\% } & \multicolumn{3}{|c|}{12,61} & \multicolumn{3}{|c|}{3,49} \\
\hline & \multicolumn{3}{|c|}{-------------------------FDA (\%)------------------------ } & \multicolumn{3}{|c|}{-------------------'Hemicelulose (\%)------------------- } \\
\hline Piatã & 46,33 abAB & $49,86 \mathrm{abA}$ & $42,22 \mathrm{abB}$ & $29,52 \mathrm{cdB}$ & 30,82 bB & $42,10 \mathrm{abA}$ \\
\hline Piatã+N & 41,64 bcB & 50,36 abA & $46,73 \mathrm{abAB}$ & $26,30 \mathrm{~dB}$ & 29,69 bAB & 31,70 cA \\
\hline Piatã+Guandu & $37,71 \mathrm{cC}$ & $52,18 \mathrm{aA}$ & $45,62 \mathrm{abB}$ & 32,44 bcA & 19,09 cC & 23,92 deB \\
\hline Tifton & $45,83 \mathrm{abA}$ & 45,17 abcAB & 39,55 bB & 36,36 abB & $40,62 \mathrm{aB}$ & 46,96 aA \\
\hline Tifton $+\mathrm{N}$ & $42,23 \mathrm{bcB}$ & $42,18 \mathrm{cB}$ & 48,89 aA & $41,72 \mathrm{aA}$ & 42,30 aA & 37,98 bA \\
\hline Tifton+Guandu & 52,08 aA & 47,11 abcAB & $44,36 \mathrm{abB}$ & $19,46 \mathrm{eB}$ & $28,23 \mathrm{bA}$ & 26,65 cdA \\
\hline Guandu & 41,71 bcA & 43,18 bcA & $45,23 \mathrm{abA}$ & $4,44 \mathrm{fB}$ & $17,07 \mathrm{cA}$ & 19,87 eA \\
\hline CV1\% & \multicolumn{3}{|c|}{7,36} & \multicolumn{3}{|c|}{10,56} \\
\hline \multirow[t]{2}{*}{$\mathrm{CV} 2 \%$} & \multicolumn{3}{|c|}{7,66} & \multicolumn{3}{|c|}{9,05} \\
\hline & \multicolumn{3}{|c|}{---------------------Celulose (\%)--------------------- } & \multicolumn{3}{|c|}{-Lignina (\%)---------------------- } \\
\hline Piatã & 37,06 abA & 36,16 abAB & $31,41 \mathrm{aA}$ & 11,16 aA & $10,20 \mathrm{aA}$ & $5,75 \mathrm{cB}$ \\
\hline Piatã+N & 26,34 cC & $40,32 \mathrm{aA}$ & $31,84 \mathrm{aB}$ & 6,72 bcA & 6,93 bA & $9,03 \mathrm{abA}$ \\
\hline Piatã+Guandu & 30,98 bcA & 34,37 abA & 35,18 aA & 8,77 abcA & $7,46 \mathrm{abA}$ & 6,43 bcA \\
\hline Tifton & 30,81 bcA & $34,09 \mathrm{abA}$ & $32,92 \mathrm{aA}$ & 9,21 abA & 6,53 bB & 7,61 abcAB \\
\hline Tifton+N & 31,20 bcA & 32,11 bA & 32,99 aA & 11,65 aA & $7,35 \mathrm{abB}$ & 7,42 abcB \\
\hline Tifton+Guandu & 39,28 aA & 37,09 abA & $34,08 \mathrm{aA}$ & $10,51 \mathrm{aA}$ & $6,72 \mathrm{bB}$ & 10,37 aA \\
\hline Guandu & $26,89 \mathrm{cB}$ & 32,28 bA & $32,70 \mathrm{aA}$ & $5,99 \mathrm{cB}$ & 7,03 bAB & $9,08 \mathrm{abA}$ \\
\hline CV1\% & \multicolumn{3}{|c|}{11,61} & \multicolumn{3}{|c|}{16,09} \\
\hline CV2\% & \multicolumn{3}{|c|}{9,40} & \multicolumn{3}{|c|}{16,91} \\
\hline
\end{tabular}

*Valores seguidos de mesma letra, maiúscula na linha e minúscula na coluna, não diferem entre si pelo teste Tukey a 5\%. PB: proteína bruta; FDN: fibra em detergente neutro; FDA: fibra em detergente ácido. CV1 (\%): coeficiente de variação da parcela; CV2 (\%): coeficiente de variação da sub-parcela. 
Tabela 3 - Produção de matéria seca (MS) dos capins Tifton 85 e Piatã e do feijão-guandu em cultivo singular ou associação

\begin{tabular}{|c|c|c|c|c|}
\hline \multirow{2}{*}{ Tratamento } & \multicolumn{4}{|c|}{---MS do consórcio $\left(\mathrm{kg} \mathrm{ha}^{-1}\right)--$} \\
\hline & $1^{0}$ Corte & $2^{0}$ Corte & $3^{0}$ Corte & Médias \\
\hline Piatã & 7443abB & $13787 \mathrm{aA}$ & 12365abA & 11198 \\
\hline Piatã+N & 6455abB & 10551abA & 13674aA & 10227 \\
\hline Piatã+Guandu & $9215 \mathrm{aB}$ & 14230aA & 12997aA & 12147 \\
\hline Tifton & 5690abB & 8956bA & 10868abA & 8505 \\
\hline Tifton $+\mathrm{N}$ & 6578abB & 9336bA & $12935 \mathrm{aA}$ & 9616 \\
\hline Tifton+Guandu & 9158aA & 9492bA & 8628bA & 9092 \\
\hline Guandu & $3412 \mathrm{bA}$ & 3366cA & 2602cA & 3127 \\
\hline Médias & 6850 & 9960 & 10581 & \\
\hline CV1\% & \multicolumn{4}{|c|}{20,01} \\
\hline CV2\% & \multicolumn{4}{|c|}{21,62} \\
\hline & & -------MS d & $\mathrm{g} \mathrm{ha}^{-1}$ ) ----- & \\
\hline Piatã & $7443 \mathrm{aB}$ & 13787aA & 12365aA & 11198 \\
\hline Piatã $+N$ & $6455 \mathrm{aB}$ & 10551abA & $13674 \mathrm{aA}$ & 10227 \\
\hline Piatã+Guandu & $5662 \mathrm{aB}$ & 10716abA & $10157 \mathrm{aA}$ & 8845 \\
\hline Tifton & $5690 \mathrm{aB}$ & 8956bcAB & 10868aA & 8505 \\
\hline Tifton $+\mathrm{N}$ & $6578 \mathrm{aB}$ & 9336bcB & $12935 \mathrm{aA}$ & 9616 \\
\hline Tifton+Guandu & 6039aA & 5777cA & $5848 \mathrm{bA}$ & 5888 \\
\hline Médias & 6311 & 9854 & 10974 & 9046 \\
\hline CV1\% & \multicolumn{4}{|c|}{19,95} \\
\hline $\mathrm{CV} 2 \%$ & \multicolumn{4}{|c|}{22,90} \\
\hline & & -----MS do f & $\left(\mathrm{kg} \mathrm{ha}^{-1}\right)-$ & \\
\hline Piatã+Guandu & 3552 & 3514 & 2841 & $3302 a$ \\
\hline Tifton+Guandu & 3118 & 3715 & 2780 & $3204 a$ \\
\hline Guandu & 3412 & 3366 & 2602 & $3127 a$ \\
\hline Médias & $3361 \mathrm{~A}$ & $3531 \mathrm{~A}$ & 2741B & \\
\hline CV1\% & \multicolumn{4}{|c|}{14,87} \\
\hline $\mathrm{CV} 2 \%$ & \multicolumn{4}{|c|}{12,21} \\
\hline
\end{tabular}

*Valores seguidos de mesma letra, maiúscula na linha e minúscula na coluna, não diferem entre si pelo teste Tukey a 5\% de probabilidade. CV1 (\%): coeficiente de variação da parcela; CV2 (\%): coeficiente de variação da sub-parcela.

voluntário e reduz a digestibilidade pelo balanço nitrogenado negativo (SANTOS et al., 2008), as forragens obtidas podem atender satisfatoriamente aos requerimentos protéicos mínimos de ruminantes.

Os teores de FDN da forragem obtida com as associações foram inferiores aos das gramíneas em monocultivo, reforçando as contribuições positivas da presença da leguminosa na qualidade da forragem. Para o feijão-guandu em monocultivo, os valores de FDN foram inferiores aos das gramíneas e das associações, por se tratar de uma espécie de ciclo $\mathrm{C}_{3}$.

Os teores de FDA apresentaram grande variação entre os cortes, com valores entre 37,7 a $52,18 \%$. Os teores de hemicelulose foram inferiores no capim Piatã, no Tifton em cultivo consorciado e no feijão-guandu, porém apresentaram grandes variações entre os cortes. Em células maduras, as hemiceluloses encontram-se mais associadas à lignina por ligações covalentes, tornado-se indisponíveis à solubilização e reduzindo a digestibilidade da forragem, evidenciando, dessa forma, a importância do momento adequado do corte ou pastejo. O teores de celulose variaram entre 30,63 e 36,82\%, porém, estes se mantiveram dentro da faixa descrita por VAN SOEST (1994), que descreve que os teores de celulose variam de 20 a $40 \%$. Os valores de lignina foram superiores no capim Piatã sem N (9,04\%) e capim Tifton 85 + feijão-guandu (9,20\%) nos três cortes avaliados. A presença de lignina tem efeitos negativos sobre a digestibilidade da foragem produzida, conforme relatado por BARBERO et al. (2010). Segundo esses autores, apesar de os valores de FDN serem baixos na forragem produzida por leguminosas, a digestibilidade é baixa devido às leguminosas apresentarem alta concentração de lignina em sua constituição, que reduz sua digestibilidade.

A produção média de MS do feijão-guandu foi de 3127kg ha-1, inferior à produção das gramíneas, 
enquanto, para os consórcios, o feijão-guandu não contribuiu para elevar a produção de MS total das associações (Tabela 3). Entretanto, sua presença na pastagem teve papel fundamental nos indicadores do valor nutritivo da forragem produzida, contribuindo com o aumento dos teores de proteína bruta e redução dos teores de FDN (Tabela 2). No consórcio, o capim Tifton 85 apresentou produção de MS inferior, devido à sua baixa tolerância ao sombreamento. CARVALHO et al. (2002), ao estudarem os capins Tifton 68 e $\boldsymbol{B}$. brizantha, constataram a intolerância do Tifton 68 ao sombreamento por meio da redução na produção de MS, enquanto a $\boldsymbol{B}$. brizantha apresentou tolerância moderada. Em monocultivo ou consorciado com as gramíneas, o feijão-guandu apresentou produção de MS semelhante, porém, com o passar dos cortes, observou-se uma redução na produção de MS, devido ao envelhecimento da forrageira, classificada como perene de vida curta (DEMINICIS, 2009).

Considerando a composição bromatológica e a produção de forragem, a substituição do $\mathrm{N}$ pelo consórcio com feijão-guandu mostrou-se uma alternativa promissora. Além da redução de custos com insumos (adubação nitrogenada) em pastagens de capim Piatã e Tifton 85, o consórcio com a leguminosa feijão-guandu é uma alternativa para aumentar a sustentabilidade dos sistemas de produção ruminantes, especialmente dos sistemas orgânicos.

\section{CONCLUSÃO}

Enquanto o uso da adubação nitrogenada promove aumentos na produção de matéria seca do capim Tifton 85, a associação deste e do capim Piatã com o feijão-guandu eleva os teores de proteína e reduz os teores de fibra em detergente neutro, devido à participação da leguminosa na forragem produzida.

O capim Tifton 85 não é tolerante ao sombreamento imposto pelo feijão-guandu, e são necessários novos estudos para identificar as alterações morfológicas que ocorrem nas gramíneas, bem como estabelecer os espaçamentos e densidades de plantas de feijão-guandu, mais adequados para os sistemas de cultivo consorciados.

\section{REFERÊNCIAS}

ALMEIDA, R.G. et al. Disponibilidade, composição botânica e valor nutritivo da forragem de pastos consorciados, sob três taxas de lotação. Revista Brasileira de Zootecnia, v.32, p.36-46, 2003. Disponível em: <http://dx.doi.org/10.1590/ S1516-35982003000100005>. Acesso em: 10 jun. 2010. doi: 10.1590/S1516-35982003000100005.
AROEIRA, L.J.M. et al. Disponibilidade, composição bromatológica e consumo de matéria seca em pastagem consorciada de Brachiaria decumbens com Stylosanthes guianensis. Pesquisa Agropecuária Brasileira, v.40, n.4, p.413-418, 2005. Disponível em: <http://dx.doi.org/10.1590/ S0100-204X2005000400014>. Acesso em: 15 jun. 2010. doi: 10.1590/S0100-204X2005000400014.

ASSOCIATION OF OFFICIAL ANALYTICAL CHEMISTS AOAC. Official methods of analysis. 15.ed. Virginia: Arlington, 1990. 1117p.

BARBERO, L.M. et al. Produção animal e valor nutritivo da forragem de pastagem de coastcross consorciada com amendoim forrageiro. Arquivos Brasileiros de Medicina Veterinária e Zootecnia, v.62, p.645-653, 2010. Disponível em: <http:/ /dx.doi.org/10.1590/S1516-35982009000500002>. Acesso em: 03 jun. 2010. doi: 10.1590/S1516-35982009000500002.

BARBOSA, R.A. et al. Capim-tanzânia submetido a combinações entre intensidade e freqüência de pastejo. Pesquisa Agropecuária Brasileira, v.42, p.329-340, 2007. Disponível em: <http://dx.doi.org/10.1590/S0100204X2007000300005>. Acesso em: 08 jun. 2010. doi: 10.1590/S0100-204X2007000300005.

BARCELLOS, A.O. et al. Sustentabilidade da produção animal baseada em pastagens consorciadas e no emprego de leguminosas exclusivas, na forma de banco de proteína nos trópicos brasileiros. Revista Brasileira de Zootecnia, v.37, p.51-67, 2008. Disponível em: <http://dx.doi.org/10.1590/S151635982008001300008>. Acesso em: 15 jun. 2010. doi: 10.1590/ S1516-35982008001300008.

CANDIDO, M.J.D. et al. Período de descanso, valor nutritivo e desempenho animal em pastagem de Panicum maximum cv. 'Mombaça' sob lotação intermitente. Revista Brasileira de Zootecnia, v.34, p.1459-1467, 2005. Disponível em: <http:/ /dx.doi.org/10.1590/S1516-35982005000700003>. Acesso em: 10 jun. 2010. doi: 10.1590/ S1516-35982005000700003.

CARNEVALLI, R.A. et al. Herbage production and grazing losses in Panicum maximum cv. 'Mombaça' under four grazing managements. Tropical Grasslands, v.40, p.165-176, 2006. Disponível em: <http://www.tropicalgrasslands.asn.au/ Tropical\%20Grasslands\%20Journal\%20archive/PDFs/ Vol_40_2006/Vol_40_03_2006_pp165_176.pdf>. Acesso em: 28 jun. 2010.

CARVALHO, M.M. et al. Início de florescimento, produção e valor nutritivo de gramíneas forrageiras tropicais sob condição de sombreamento natural. Pesquisa Agropecuária Brasileira, v.37, p.717-722, 2002. Disponível em: <http:// dx.doi.org/10.1590/S0100-204X2002000500018>. Acesso em: 26 jun. 2010. doi: 10.1590/S0100-204X2002000500018.

COSTA, K.A. et al. Efeito da estacionalidade na produção da matéria seca e composição bromatológica da Brachiaria brizantha cv. 'Marandu'. Ciência Animal Brasileira, v.6, p.187-193, 2005. Disponível em: <http:// h200137221174.ufg.br/bitstream/123456789/138/1/ efeito\%20da\%20estacionalidade.pdf>. Acesso em: 26 jun. 2010.

DEMINICIS, B.B. Leguminosas forrageiras tropicais: características importantes, recursos genéticos e causas dos insucessos de pastagens consorciadas. Viçosa: Aprenda Fácil, 2009. 167p. 
EMBRAPA. Centro Nacional de Pesquisa de Solos. Sistema brasileiro de classificação de solos. 2 ed. Rio de Janeiro: Embrapa Solos, 2006. 306p.

EMBRAPA. Empresa Brasileira de Pesquisa Agropecuária. Manual de métodos de análise de solo. Rio de Janeiro: Centro Nacional de Pesquisa de Solos, 1997. 212p.

GOBBI, K.F. et al. Características morfológicas, estruturais e produtividade do capim-braquiária e do amendoim forrageiro submetidos ao sombreamento. Revista Brasileira de Zootecnia, v.38, n.9, p.1645-1654, 2009. Disponível em: <http://dx.doi.org/10.1590/S1516-35982009000900002>. Acesso em: 18 ago. 2010. doi: 10.1590/S151635982009000900002 .

GOMIDE, C.A.M. et al. Características estruturais e produção de forragem em pastos de capim-mombaça submetidos a períodos de descanso. Pesquisa Agropecuária Brasileira, v.42, p.1487-1494, 2007. Disponível em: <http://dx.doi.org/ 10.1590/S0100-204X2007001000017>. Acesso em: 10 jul. 2010. doi: 10.1590/S0100-204X2007001000017.

GONTIJO NETO, M.M. et al. Consumo e tempo diário de pastejo por novilhos Nelore em pastagem de capim-tanzânia sob diferentes ofertas de forragem. Revista Brasileira de Zootecnia, v.35, n.1, p.60-66, 2006. Disponível em: <http:/ /dx.doi.org/10.1590/S1516-35982006000100007>. Acesso em: 8 jul. 2010. doi: 10.1590/S1516-35982006000100007.

INSTITUTO AGRONÔMICO DO PARANÁ - IAPAR. Cartas climáticas do Paraná. 2006. Disponível em: <http:// $200.201 .27 .14 / \mathrm{S}$ ite/S ma/Cartas Climaticas/ Classificação_Climaticas.htm>. Acesso em: 03 set. 2008.

MONTEIRO, H.C.F. et al. Dinâmica de decomposição e mineralização de nitrogênio em função da qualidade de resíduo de gramíneas e leguminosas forrageiras. Revista Brasileira de Zootecnia, v.31, p.1092-1102, 2002. Disponível em <http://dx.doi.org/10.1590/S1516-35982002000500005>. Acesso em: 15 jul. 2010. doi: 10.1590/S151635982002000500005 .

PEREIRA, O.G. et al. Características morfogênicas e estruturais do capim-tifton 85 sob doses de nitrogênio e alturas de corte. Revista Brasileira de Zootecnia, v.40, n.9, p. 1870-1878, 2011. Disponível em: <http://dx.doi.org/10.1590/S1516-
35982011000900005>. Acesso em: 11 nov. 2011. doi: 10.1590/ S1516-35982011000900005.

PIMENTEL-GOMES, F.P. Curso de estatística experimental. 15.ed. Piracicaba: FEALQ, 2009. 451p.

PREMAZZI, L.M. et al. Crescimento de folhas do capimbermuda tifton 85 submetido à adubação nitrogenada após o corte. Revista Brasileira de Zootecnia, v.40, n.3, p. 518526, 2011. Disponível em: <http://dx.doi.org/10.1590/S151635982011000300008>. Acesso em: 08 nov. 2011. doi: 10.1590/ S1516-35982011000300008.

SANTOS, M.V. et al. Controle de Brachiaria brizantha com uso do glyphosate após o estabelecimento de Tifton 85 (Cynodon spp.). Planta Daninha, v.24, p.813-819, 2006. Disponível em: <http://dx.doi.org/10.1590/S010083582006000400023>. Acesso em: 05 jun. 2010. doi: 10.1590/ S0100-83582006000400023.

SANTOS, N.L. et al. Efeito da irrigação suplementar sobre a produção dos capins tifton 85, tanzânia e marandu no período de verão no sudoeste baiano. Ciência Animal Brasileira, v.9, p.911-922, 2008. Disponível em: <http:// www.revistas.ufg.br/index.php/vet/article/view/1183>. Acesso em: 05 nov. 2011

SILVA, D.J.; QUEIROZ, A.C. Análise de alimentos: métodos químicos e biológicos. Viçosa: UFV, 2006. 235p.

SILVEIRA, M.C.T. et al. Morphogenetic and structural comparative characterization of tropical forage grass cultivars under free growth. Scientia Agricola, v.67, n.2, p.136-142, 2010. Disponível em: <http://dx.doi.org/10.1590/S010390162010000200002>. Acesso em: 20 nov. 2008. doi: 10.1590/S0103-90162010000200002.

SOARES, A.B. et al. Influência da luminosidade no comportamento de onze espécies forrageiras perenes de verão. Revista Brasileira de Zootecnia, v.38, p. 443-451, 2009. Disponível em: <http://dx.doi.org/10.1590/S151635982009000300007>. Acesso em: 20 nov. 2008. doi: 10.1590/S1516-35982009000300007.

VAN SOEST, P.J. Nutritional ecology of the ruminant. Ithaca: Constock Publishing Associates, 1994. 476p. 